\title{
Ultra-porous titanium oxide scaffold with high compressive strength
}

\author{
Hanna Tiainen · S. Petter Lyngstadaas • \\ Jan Eirik Ellingsen $\cdot$ Håvard J. Haugen
}

Received: 23 February 2010/Accepted: 3 August 2010/Published online: 14 August 2010

(C) The Author(s) 2010. This article is published with open access at Springerlink.com

\begin{abstract}
Highly porous and well interconnected titanium dioxide $\left(\mathrm{TiO}_{2}\right)$ scaffolds with compressive strength above 2.5 MPa were fabricated without compromising the desired pore architectural characteristics, such as high porosity, appropriate pore size, surface-to-volume ratio, and interconnectivity. Processing parameters and pore architectural characteristics were investigated in order to identify the key processing steps and morphological properties that contributed to the enhanced strength of the scaffolds. Cleaning of the $\mathrm{TiO}_{2}$ raw powder removed phosphates but introduced sodium into the powder, which was suggested to decrease the slurry stability. Strong correlation was found between compressive strength and both replication times and solid content in the ceramic slurry. Increase in the solid content resulted in more favourable sponge loading, which was achieved due to the more suitable rheological properties of the ceramic slurry. Repeated replication process induced only negligible changes in the pore architectural parameters indicating a reduced flaw size in the scaffold struts. The fabricated $\mathrm{TiO}_{2}$ scaffolds show great promise as load-bearing bone scaffolds for applications where moderate mechanical support is required.
\end{abstract}

H. Tiainen · S. P. Lyngstadaas $\cdot$ H. J. Haugen $(\bowtie)$ Department of Biomaterials, Institute for Clinical Dentistry, University of Oslo, PO Box 1109, Blindern, 0317 Oslo, Norway e-mail: h.j.haugen@odont.uio.no

J. E. Ellingsen

Oral Research Laboratory, Institute for Clinical Dentistry, University of Oslo, PO Box 1109, Blindern, 0317 Oslo, Norway

\section{Introduction}

Bone tissue engineering offers an alternative strategy for restoring damaged, diseased, and resorbed bone tissue. In this approach, natural bone tissue is generated from osteogenic cells to replace the missing tissue with the aid of a porous three-dimensional scaffold $[1,2]$. For the repair and regeneration of bone tissue, the 3D scaffold structure must provide bone forming cells a substrate to attach to and allow the newly formed tissue adequate space for growth [3]. Hence, highly porous scaffolds with high surface-tovolume ratio are necessary for bone tissue engineering applications [4-6]. A large surface area-to-volume ratio assists cell attachment and growth and is therefore necessary in order to achieve a high cell density within the scaffold, whereas a large interconnected pore volume is required in order to allow bone cells to migrate into and subsequently proliferate within the scaffold interior [7-10].

Together with the physical properties of the scaffold material, the pore architecture also determines the mechanical properties of the 3D scaffold structure. A bone scaffold construct should match as closely as possible the mechanical properties of natural bone and provide sufficient support for the repair site in a load-bearing environment [11-13]. Because increased porosity and pore size result in reduced mechanical properties and, consequently, diminish the structural integrity of the scaffold, there is a practical upper limit for the porosity and the pore size that can be tolerated $[6,14]$.

Titanium dioxide $\left(\mathrm{TiO}_{2}\right)$ is a biocompatible material, which has also been reported to have bioactive properties $[15,16]$. Ceramic $\mathrm{TiO}_{2}$ is therefore a promising material for scaffolds for tissue engineering purposes. Fabrication of highly porous $\mathrm{TiO}_{2}$ scaffolds with a well interconnected pore network and the ability to promote fibroblast and 
osteoblast cell adhesion onto the entire scaffold surface has previously been reported [17, 18]. However, these scaffolds have limited mechanical properties and may thus have inadequate strength to serve as scaffolds in applications where good mechanical support is required. Furthermore, differences have been found in the cytotoxicity of different $\mathrm{TiO}_{2}$ raw powders that can be used in the fabrication of the scaffolds [19]. Based on the results presented in the aforementioned study, Kronos $\mathrm{TiO}_{2}$ powder was selected as the most appropriate raw powder for the scaffold production.

The aim of the present study was to fabricate highly biocompatible ceramic $\mathrm{TiO}_{2}$ scaffolds with improved mechanical properties suitable for bone tissue engineering applications. The objective was to produce scaffolds with compressive strength values above $2 \mathrm{MPa}$, which can be considered as the lower limit for the compressive strength of trabecular bone, and also to identify the key manufacturing steps that govern the strength of such scaffolds.

\section{Materials and methods}

\section{$2.1 \mathrm{TiO}_{2}$ raw powder}

Commercial $\mathrm{TiO}_{2}$ powder (Kronos 1171, Kronos Titan $\mathrm{GmbH}$, Leverkusen, Germany) was used for the preparation of the ceramic slurry. The $\mathrm{TiO}_{2}$ powder was cleaned in $1 \mathrm{M} \mathrm{NaOH}$ solution prior to use. The cleaning was performed by soaking the $\mathrm{TiO}_{2}$ powder in $1 \mathrm{M} \mathrm{NaOH}$ and subsequently rinsing it in deionised $\mathrm{H}_{2} \mathrm{O}$. The water was drained out and the powder was dried at $70^{\circ} \mathrm{C}$ for at least $24 \mathrm{~h}$ prior to sieving (Analysette 3, Fritsch $\mathrm{GmbH}$, IdarOberstein, Germany). After sieving, powder with particle sizes between 50 and $100 \mu \mathrm{m}$ was collected and used for the preparation of the ceramic slurry.

\subsection{Scaffold fabrication}

The ceramic slurry for scaffold fabrication was prepared by gradually adding 60 or $65 \mathrm{~g}$ of $\mathrm{TiO}_{2}$ powder to $25 \mathrm{ml}$ of sterilised water and the $\mathrm{pH}$ of the slurry was kept at 1.7 for the entire duration of the stirring with small additions of $1 \mathrm{M} \mathrm{HCl}$. For double-coated scaffolds, the slurry for the second coating contained $40 \mathrm{~g}$ of $\mathrm{TiO}_{2}$ powder in $25 \mathrm{ml}$ sterilised water. The $\mathrm{TiO}_{2}$ powder was stirred in to the water in several steps at low rotation speed of $1,000 \mathrm{rpm}$ (Dispermat Ca-40, VMA-Getzmann GmbH, Reichshof, Germany). The temperature of the slurry was adjusted to room temperature during the low rotation speed stirring. When the slurry mixture was homogenous, the rotation speed was increased to 5,000 rpm and the slurry was stirred for $5 \mathrm{~h}$ at this rotation speed. Temperature of the slurry was reduced to $15^{\circ} \mathrm{C}$ during high speed stirring.

The polyurethane (PU) foam templates (60 ppi, Bulbren $\mathrm{S}$, Eurofoam $\mathrm{GmbH}$, Wiesbaden, Germany) were washed and cut to appropriate size as described in [18]. The cylindrical templates were then immersed in the ceramic slurry, and excess slurry was either squeezed between two polymer foam sheets or centrifuged (1 min @ 1,000 rpm; Biofuge 22R Heraeus Sepatech, Osterode, Germany) out of the foam templates to ensure that only a thin layer of slurry covered uniformly the entire surface area of the polymer template without blocking the pores. The samples were then placed on a porous ceramic plate and allowed to dry at room temperature for at least $16 \mathrm{~h}$ before sintering.

For the burnout of the polymer, the scaffolds were slowly heated to $450^{\circ} \mathrm{C}$ at a heating rate of $0.5 \mathrm{~K} / \mathrm{min}$. After $1 \mathrm{~h}$ holding time at $450^{\circ} \mathrm{C}$, temperature was raised to $1,500^{\circ} \mathrm{C}$ at a rate of $3 \mathrm{~K} / \mathrm{min}$ and the sintering time at this temperature was set to $40 \mathrm{~h}$. The sintered scaffolds were then cooled back to room temperature at the cooling rate of $5 \mathrm{~K} / \mathrm{min}$ (HTC08/16, Nabertherm GmbH, Bremen, Germany).

\subsection{Material characterisation}

The chemical surface compositions of both as-received and cleaned Kronos $\mathrm{TiO}_{2}$ raw powders were investigated by the means of X-ray photoelectron spectroscopy (XPS in a KRATOS AXIS ULTRA ${ }^{\text {DLD }}$, Kratos Analytical, Manchester, UK) using monochromatic $\mathrm{Al} \mathrm{K} \alpha$ radiation ( $h v=$ $1,486.6 \mathrm{eV})$. The XPS data analysis was performed using the CasaXPS (computer-aided surface analysis for X-ray photoelectron spectroscopy) software package (Casa Software Ltd., UK).

The particle size distribution of the $\mathrm{TiO}_{2}$ slurry was determined by the means of laser diffraction (Mastersizer 2000, Malvern Instruments, UK). Samples were collected for particle size measurement at several time points during high speed stirring $(5,000 \mathrm{rpm})$.

The crystal structure of the sintered $\mathrm{TiO}_{2}$ scaffolds was examined by X-ray diffraction (XRD), performed with a Siemens D5000 X-ray diffractometer equipped with a Göbel-mirror providing parallel $\mathrm{Cu} \mathrm{K} \alpha$ radiation (Siemens, Munich, Germany). The acquisition was done using grazing incidence configuration.

\subsection{Pore morphology}

The initial visualisation and optical observation of the microstructure of the prepared scaffolds were performed using a scanning electron microscope (TM-1000, Hitachi High-Technologies, Tokyo, Japan). The scaffolds were mounted on aluminium stubs with conductive carbon tape 
and viewed with backscattered secondary ions at $15 \mathrm{kV}$ accelerating voltage.

Micro-computed tomography was used to determine non-destructively the three-dimensional microstructure, porosity, and porous interconnectivity of the scaffolds. The samples were mounted vertically on a plastic sample holder and scanned with desktop 1172 micro-CT imaging system (Skyscan, Kontich, Belgium) at $6 \mu \mathrm{m}$ voxel resolution using a source voltage of $100 \mathrm{kV}$ and a current of $100 \mu \mathrm{A}$ with $0.5 \mathrm{~mm}$ aluminium filter. Samples were rotated $180^{\circ}$ around their long axis and three absorption images were recorded every $0.400^{\circ}$ of rotation. These raw images of the samples were reconstructed with the standard SkyScan reconstruction software (NRecon) to serial coronal-oriented tomograms using 3D cone beam reconstruction algorithm. For the reconstruction, beam hardening was set to $20 \%$ and ring artefact reduction to 12 .

The image analysis of the reconstructed axial bitmap images was performed using the standard SkyScan software (CTan and CTvol). First, a thresholding analysis was performed to determine the threshold value for which the greyscale tomograms of scaffolds were most accurately represented by their binarised counterparts in terms of porosity. The threshold value was set between 65 and 255 for this study. Additional noise was removed by the 'despeckling' function. All objects smaller than 500 voxels and not connected to the $3 \mathrm{D}$ body were thus removed prior to further analysis. In order to eliminate potential edge effects, a cylindrical volume of interest (VOI) with a diameter of $5 \mathrm{~mm}$ and a height of $2.5 \mathrm{~mm}$ was selected in the centre of the scaffold. Scaffold porosity was then calculated as follows:

$$
\begin{aligned}
\text { Porosity }= & 100 \%-\text { vol. } \% \text { of binarised object } \\
& (\text { scaffold material }) \text { in VOI }
\end{aligned}
$$

All images underwent 3D analysis, followed by the quantification of interconnectivity using the 'shrink-wrap' function, which allows measuring the fraction of pore volume in a scaffold that is accessible from the outside through openings of a certain minimum size [20]. A shrinkwrap process was performed between two 3D measurements to shrink the outside boundary of the VOI in a scaffold through any opening the size of which is equal to or larger than a threshold value (0-190 $\mu \mathrm{m}$ were used in this study). Interconnectivity was calculated as follows:

Interconnectivity $=\frac{V-V_{\text {shrink-wrap }}}{V-V_{\mathrm{m}}} \times 100 \%$,

where $V$ is the total volume of VOI, $V_{\text {shrink-wrap }}$ is the VOI volume after shrink-wrap processing, and $V_{\mathrm{m}}$ is the volume of scaffold material.

The mean pore diameter distribution was found by measuring the material thickness on the inverse model, which was generated by setting the threshold value between 0 and 65 . Additional noise was again removed using the 'despeckling' function, which removed all objects smaller than 500 voxels and not connected to the 3D body. 3D models of the scaffolds were generated through algorithm adaptive rendering.

\subsection{Compressive strength}

Compressive mechanical testing (Zwicki, Zwick/Roell, Ulm, Germany) was conducted to evaluate the mechanical strength of the prepared scaffolds. Compression tests were performed in accordance with DIN EN ISO 3386 at room temperature using a load cell of $1.0 \mathrm{kN}$. The preloading force was set to be $0.5 \mathrm{~N}$. The scaffolds were compressed along their length axis at a compression speed of $100 \mathrm{~mm} /$ min until failure. The force and displacement were recorded throughout the compression and converted to stress and strain based on the initial scaffold dimensions.

\subsection{Statistical analyses}

Different data groups were compared through a one-way analysis of variance (one-way ANOVA) test followed by post hoc tests for pairwise comparisons (Holm-Sidak method). Normality and equal variance tests were performed prior to the testing. Statistical significance was considered at a probability $P<0.05$. A correlation study was performed with a bivariate regression analysis, Spearman Rank Order correlation, using the computer software SigmaStat version 3.5 (Symantec, St. Louis, USA). The results were interpreted as follows: small correlation if $0.1<|r|<0.3$; medium correlation if $0.3<|r|<0.5$; and strong correlation if $0.5<|r|<1$ [21]. A negative $r$ indicated a negative correlation, whereas a positive $r$ indicated a positive correlation.

\section{Results}

\subsection{Chemical surface composition of the $\mathrm{TiO}_{2}$ powder}

In order to examine the chemical surface composition of the Kronos $\mathrm{TiO}_{2}$ powder used as the raw material in scaffold fabrication, XPS measurements were performed on both as-received and cleaned powders, and the results of these measurements are given in Table 1. In addition to titanium and oxygen, some impurities, such as carbon and phosphorus, were detected in both examined powders. The as-received Kronos $\mathrm{TiO}_{2}$ powder was found to contain 1.08 at.\% of potassium, whereas no significant amount of potassium was detected in cleaned Kronos powder. Instead, a distinct quantity of sodium was measured in the cleaned 
Table 1 The chemical surface composition (at.\%) of as-received and cleaned Kronos $\mathrm{TiO}_{2}$ powders

\begin{tabular}{lllllll}
\hline Powder & $\mathrm{O}$ & $\mathrm{Ti}$ & $\mathrm{C}$ & $\mathrm{P}$ & $\mathrm{K}$ & $\mathrm{Na}$ \\
\hline As-received & 64.35 & 25.03 & 6.81 & 2.73 & 1.08 & 0 \\
Cleaned with 1 M NaOH & 55.91 & 24.74 & 11.94 & 0.94 & 0 & 6.48 \\
\hline
\end{tabular}

powder. Also, the amount of phosphorus contaminants was reduced due to the cleaning process from 2.73 at.\% in asreceived Kronos powder to 0.94 at.\% in cleaned powder.

\subsection{Particle size and stability of the $\mathrm{TiO}_{2}$ slurry}

The particle size distribution of the prepared $\mathrm{TiO}_{2}$ slurry was measured at several time points during the dispersion process. Curiously, the mean particle size stopped decreasing already after $1 \mathrm{~h}$ of high speed stirring at $5,000 \mathrm{rpm}$ (Fig. 1). Instead, the mean particle size was slightly increased after $2 \mathrm{~h}$ milling time after which the particle size distribution started fluctuating slightly. However, the shape of the distribution curve remained virtually the same until $6.5 \mathrm{~h}$ milling time was reached. After $6.5 \mathrm{~h}$ of high speed stirring the amount of fine particles in the slurry increased, while the particle size distribution became wider (data not shown). A notable change was also observed in the slurry viscosity. After more than $6 \mathrm{~h}$ of high speed stirring, the slurry became too viscous for the impregnation of the polymer sponge templates. Overall, the dispersion process had very little effect on the particle size distribution of the slurry.

Some slurries were also prepared by dispersing the powder at $\mathrm{pH}$ 9-11, but these slurries developed such high viscosities that the slurry became too thick and unmanageable even before all the powder had been added into the

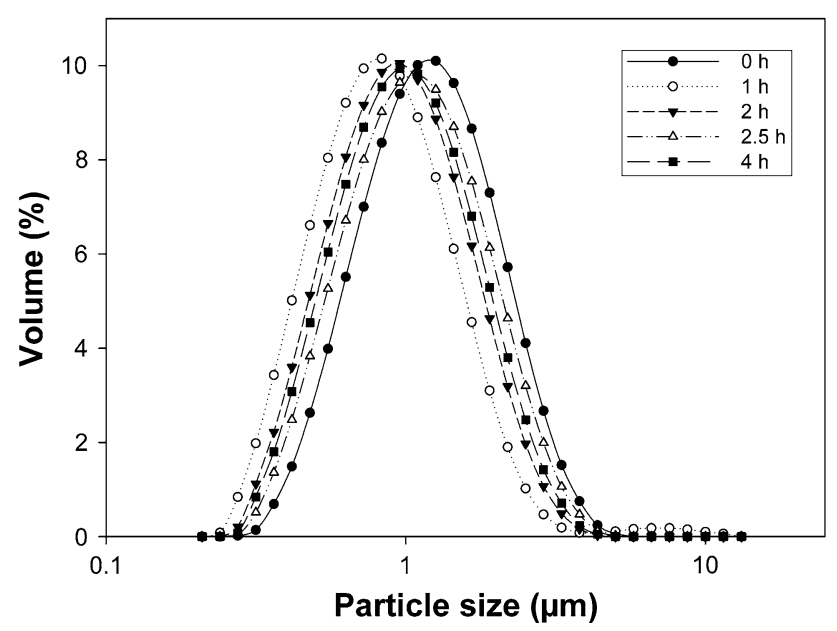

Fig. 1 Particle size distribution of the prepared $\mathrm{TiO}_{2}$ slurry at different time points during milling dispersion. Normal viscosity was only restored when $\mathrm{pH}$ was lowered to values between 1.50-1.75.

\subsection{Mechanical and pore architectural properties of the prepared scaffolds}

The typical pore structures of the as-prepared $\mathrm{TiO}_{2}$ scaffolds are shown in Fig. 2. The initial pore network of the polyurethane template was well replicated with very little blocking of the pores. The sintered ceramic foams maintained the original strut and pore shape of the template foam, and the spherical macropores of $\sim 400 \mu \mathrm{m}$ and the struts with diameters of $\sim 50-100 \mu \mathrm{m}$ formed a highly interconnected pore structure. For all three different scaffold groups, the average porosity was above $87 \%$.

There was also finer-scale porosity present at the foam struts which can be observed in Fig. 2. Triangular voids were found in the interior of some scaffold struts, whereas in most struts one wall of the triangular void left by the polymer template had collapsed, or folded in, thus eliminating the hollow space from the strut interior. Finer-scale porosity was also observed as long cracks and voids, particularly close to the stems of the scaffold struts.

In order to gather further information on the pore architectural features of the $\mathrm{TiO}_{2}$ scaffolds, micro-CT analysis was performed. The values of several pore structural parameters of the prepared $\mathrm{TiO}_{2}$ scaffolds are listed in Table 2, while Fig. 2 also presents the three-dimensional micro-CT models the pore structures of the scaffolds prepared using different processing parameters.

To assess the mechanical properties of the prepared scaffolds, compressive strength was measured and correlated with several pore architectural characteristics of the scaffolds (Table 3). The compressive strength of the $\mathrm{TiO}_{2}$ scaffolds was found to range from a lowest value of 0.31 MPa to a highest value of 3.14 MPa. Strong correlation was found between compressive strength and both porosity and pore size with lower porosities and pore sizes resulting in higher strength values. Strong correlation was also found between compressive strength and fractal dimension of the scaffold struts. Medium correlation was found with surface area-to-volume ratio and degree of anisotropy.

XRD data revealed that the sintering process used in the fabrication of the $\mathrm{TiO}_{2}$ scaffolds produced $\mathrm{TiO}_{2}$ with rutile crystalline structure (data not shown).

\subsection{The effect of processing parameters on scaffold properties}

The effect of solid content of the ceramic slurry on the compressive strength of the scaffolds may be observed in Fig. 3. Scaffolds manufactured from a ceramic slurry with a $\mathrm{TiO}_{2}$-to- $\mathrm{H}_{2} \mathrm{O}$ ratio of $2.6\left(65 \mathrm{~g} \mathrm{TiO}_{2}\right)$ displayed considerably 

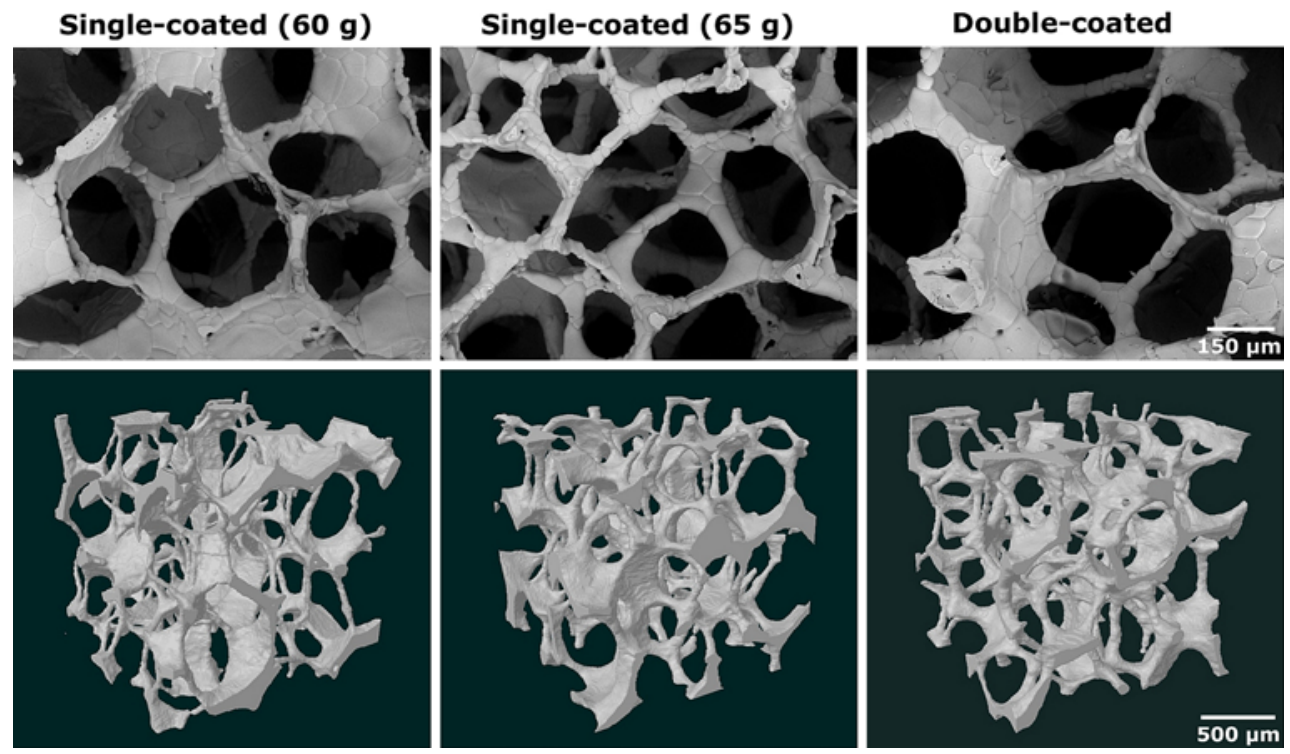

Fig. 2 SEM images and 3D micro-CT models of the prepared $\mathrm{TiO}_{2}$ foams showing the reticulated pore structure of the scaffolds. Some finerscale porosity may also be observed in the SEM images

Table 2 Selected structural parameters of the $\mathrm{TiO}_{2}$ scaffolds derived from the micro-CT data displaying the mean values \pm standard deviation $(n=20)$ for each parameter

\begin{tabular}{llccc}
\hline Parameter & Unit & \multicolumn{1}{l}{$60 \mathrm{~g}$} & $65 \mathrm{~g}$ & Double-coated \\
\hline Porosity & $\%$ & $89.6 \pm 2.1$ & $87.1 \pm 2.8$ & $87.6 \pm 2.8$ \\
Intersection surface & $\mathrm{mm}^{2}$ & $7.5 \pm 1.6$ & $8.6 \pm 2.1$ & $7.6 \pm 3.1$ \\
Surface area-to-volume ratio & $1 / \mathrm{mm}$ & $57.9 \pm 9.1$ & $53.7 \pm 5.4$ & $54.9 \pm 4.7$ \\
Pore size & $\mu \mathrm{m}$ & $410 \pm 24$ & $396 \pm 16$ & $392 \pm 14$ \\
Strut thickness & $\mu \mathrm{m}$ & $73.5 \pm 16.5$ & $70.3 \pm 9.8$ & $70.0 \pm 8.1$ \\
Structure linear density & $1 / \mathrm{mm}$ & $1.45 \pm 0.21$ & $1.85 \pm 0.17$ & $1.76 \pm 0.21$ \\
Degree of anisotropy/strut & & $1.41 \pm 0.18$ & $1.42 \pm 0.09$ & $1.40 \pm 0.08$ \\
Degree of anisotropy/pore & & $1.28 \pm 0.14$ & $1.17 \pm 0.04$ & $1.22 \pm 0.07$ \\
Fractal dimension/strut & & $2.14 \pm 0.02$ & $2.19 \pm 0.01$ & $2.17 \pm 0.01$ \\
Fractal dimension/pore & & $2.13 \pm 0.03$ & $2.14 \pm 0.02$ & $2.14 \pm 0.02$ \\
\hline
\end{tabular}

Table 3 Correlation study between compressive strength and selected pore architectural characteristics and processing parameters of the prepared scaffolds $(\mathrm{n}=55, * * P<0.01, * P<0.05)$

\begin{tabular}{|c|c|c|c|c|c|c|c|}
\hline $\begin{array}{l}\text { Spearman's correlation } \\
\text { coefficient }\end{array}$ & Porosity & $\begin{array}{l}\text { Surface area-to-volume } \\
\text { ratio }\end{array}$ & Pore size & $\begin{array}{l}\text { Degree of } \\
\text { anisotropy }\end{array}$ & $\begin{array}{l}\text { Fractal } \\
\text { dimension/strut }\end{array}$ & $\begin{array}{l}\text { Solid } \\
\text { content }\end{array}$ & $\begin{array}{l}\text { Replication } \\
\text { times }\end{array}$ \\
\hline Compressive strength & $-0.682 * *$ & $-0.397 * *$ & $-0.567 * *$ & $0.351 *$ & $0.635^{* *}$ & $0.645^{* *}$ & $0.649 * *$ \\
\hline
\end{tabular}

higher compressive strength values at equivalent porosities than those manufactured using a slurry that had a lower $\mathrm{TiO}_{2}$-to- $\mathrm{H}_{2} \mathrm{O}$ ratio $\left(60 \mathrm{~g} \mathrm{TiO}_{2}, \mathrm{TiO}_{2} / \mathrm{H}_{2} \mathrm{O}=2.4\right)$. The compressive strength was further improved when the replication process was repeated. As seen in Fig. 3, doublecoated scaffolds displayed significantly higher compressive strength values with equivalent porosity when compared to scaffolds that underwent only one replication process. In preparation of the double-coated scaffolds, ceramic slurry with $\mathrm{TiO}_{2}$-to- $\mathrm{H}_{2} \mathrm{O}$ ratio of 2.6 was used for the first replication process. Strong positive correlation was found between the compressive strength and both the solid content and the replication times (Table 3 ).

Neither the change in the solid content of the ceramic slurry nor the second replication process was observed to cause considerable differences in the overall microscopic appearance among the scaffolds. Moreover, the micro-CT analysis revealed that the porosity of the scaffolds was not markedly altered by the change in the solid content or the repeated replication process. A statistically significant difference was nevertheless found between the samples having different solid content. However, the increase in the 


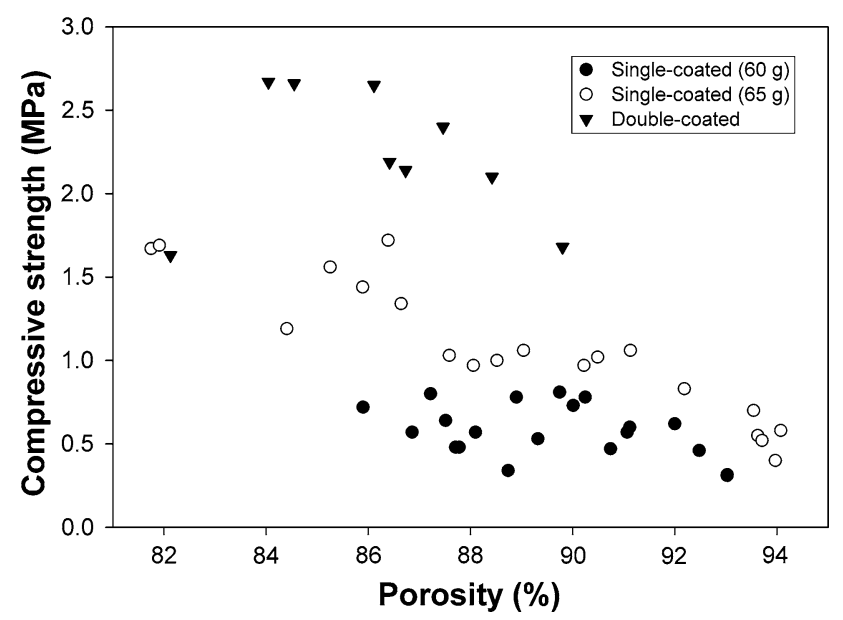

Fig. 3 Scatter plot displaying the effect of solid content in the ceramic slurry and repeated replications on the compressive strength of the prepared $\mathrm{TiO}_{2}$ scaffolds

solid content of the slurry was observed to cause only a $2.8 \%$ decrease in the average porosity (Table 2 ).

Figure 4 presents the pore diameter and strut thickness distributions for three randomly selected scaffolds that were fabricated using different processing parameters. These three scaffolds were also found representative for the three different groups. A statistically significant difference in the mean pore diameters of the scaffolds was detected between scaffolds manufactured using different powder content in the slurry. Increased solid content in the ceramic slurry caused a slight shift in the mean pore diameter towards smaller diameters. Similar effect was also noted in the pore size distribution (Fig. 4a). However, the solid content in the ceramic slurry had no significant effect on the mean strut thickness of the scaffolds. Neither was a statistical difference detected between the mean strut thicknesses of single- and double-coated scaffolds. Nevertheless, the strut thickness distribution was considerably narrower for the scaffolds that were fabricated using slurries with higher solid content (single-coated and double-coated). Furthermore, it was noted that the second replication did not have a significant effect on the strut thickness distribution (Fig. 4b). However, some changes were observed in the fractal dimension of the scaffold struts due to the difference in the processing parameters. Increase in the solid content was found to result in scaffolds with higher fractal dimensions, whereas the repeated replication led to slightly decreased fractal dimensions (Table 2). Accordingly, statistically significant difference was detected between both different solid contents and different replication times.

Figure 5 presents the results of the interconnectivity analysis of the three above-mentioned scaffolds. Each scaffold was highly interconnected with more than $98 \%$ of
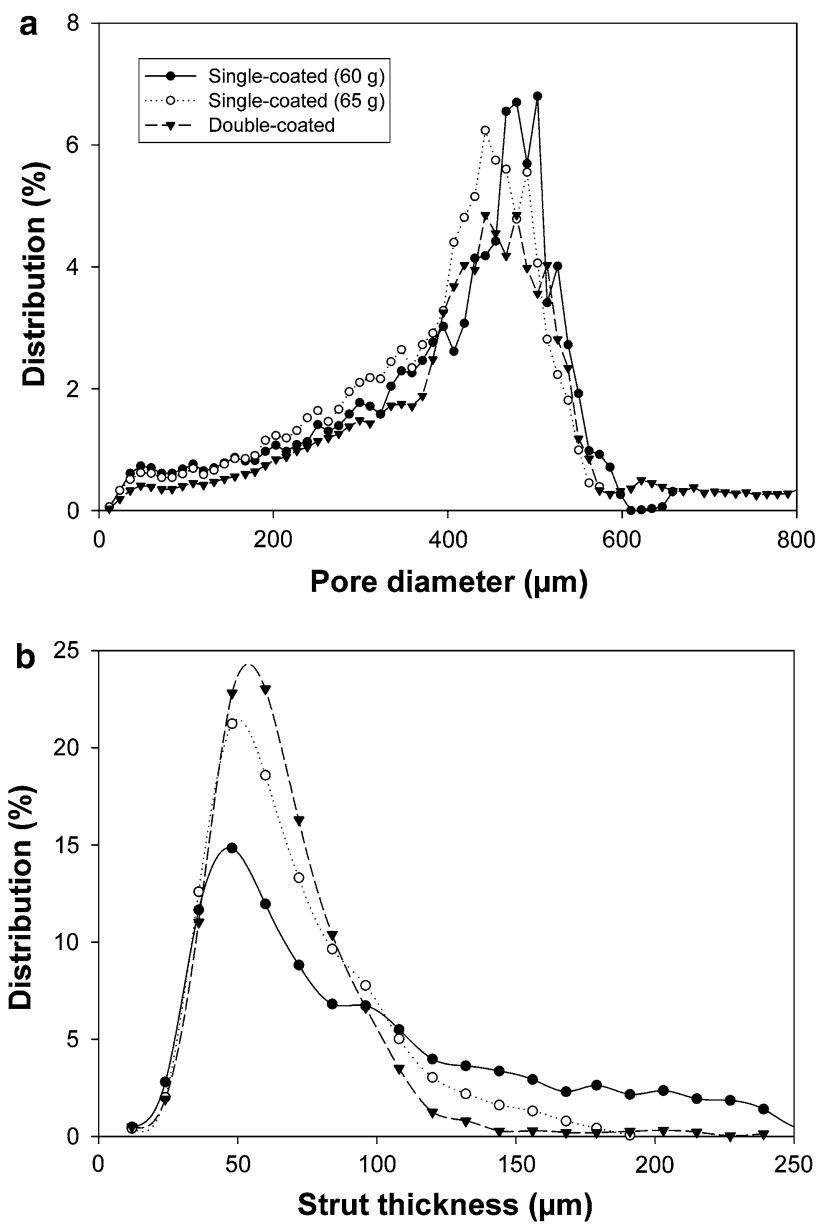

Fig. 4 Pore diameter (a) and strut thickness (b) distributions for scaffolds fabricated using different processing parameters

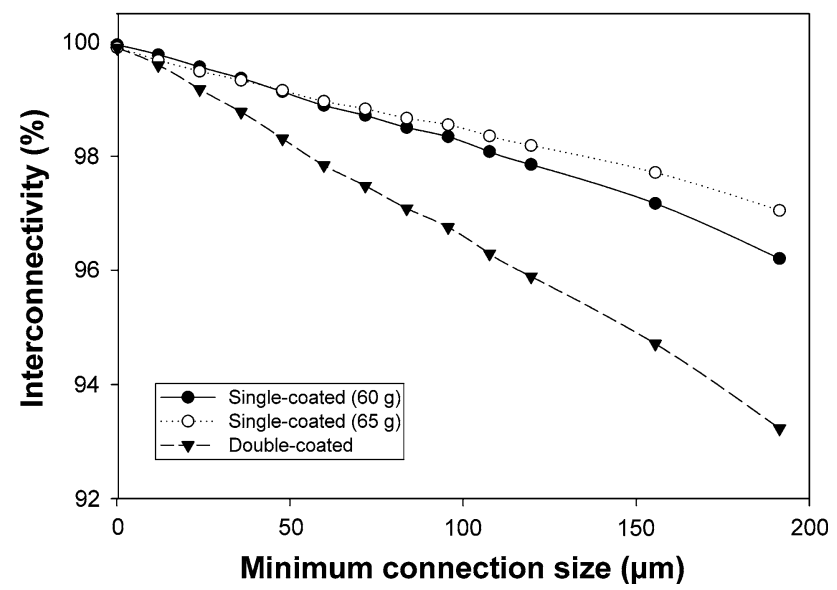

Fig. 5 Interconnectivity of three different $\mathrm{TiO}_{2}$ scaffolds through openings smaller than $190 \mu \mathrm{m}$ in diameter. Excellent interconnectivity allows the migration of bone cells as well as the exchange of nutrients and metabolism products within the scaffold interior 
the pores connected to their outside environment through openings of $50 \mu \mathrm{m}$ in diameter. Moreover, still nearly $97 \%$ interconnectivity was observed at the minimum connection size of $190 \mu \mathrm{m}$ for single-coated scaffolds. The repeated replication process caused a slight decrease in the interconnectivity of the scaffolds, which became more pronounced as the minimum connection size increased. However, the double-coated scaffolds were still more than well interconnected even through openings over $100 \mu \mathrm{m}$ in diameter. Even at minimum connection size of $190 \mu \mathrm{m}$, more than $93 \%$ of the pores in double-coated scaffolds were found interconnected.

\section{Discussion}

In previous studies, polymer sponge method has been successfully utilised in the fabrication of highly porous $\mathrm{TiO}_{2}$ bone scaffolds. However, with a maximum compressive strength of $1.2 \mathrm{MPa}$, these scaffolds lack the necessary mechanical integrity required for scaffolds intended for load-bearing applications [17, 18]. In the present study, the optimal processing parameters described in [18] were adjusted for the production of $\mathrm{TiO}_{2}$ scaffolds from cleaned Kronos $\mathrm{TiO}_{2}$ raw powder with the aim of producing ceramic foams with improved mechanical strength. Particular attention was paid on identifying the key processing parameters that may contribute to further improvement in the compressive strength of the ceramic foam structure.

\subsection{Slurry preparation}

Commercial ceramic powders often contain traces of impurities that remain from the powder manufacturing process [22]. Such impurities may interfere with the densification and thus hinder the grain growth and lead to poor consolidation of the green body [23, 24]. Adsorbed impurities on the particle surface may also interfere with the short-range forces acting between the particles, therefore altering their behaviour when dispersed in aqueous solutions [25]. Some impurities, namely phosphorus and potassium, were detected on the surface of the raw powder. Cleaning the Kronos powder with $1 \mathrm{M} \mathrm{NaOH}$ solution removed the potassium totally and considerably reduced the amount of phosphorus originally deposited on the powder surface. Moreover, the biocompatibility of sintered $\mathrm{TiO}_{2}$ samples has been found to improve due to the cleaning of the raw powder in a recent study. The cleaned Kronos $\mathrm{TiO}_{2}$ powder also performed better in terms of biocompatibility compared to several $\mathrm{TiO}_{2}$ powders from other manufacturers [19].
Ceramic slurry with fine particle size and narrow particle size distribution is generally required in order to produce ceramics with small and uniform grain size, which is known to contribute to better strength values [26, 27]. In this study, a lab dissolver was used for the dispersion and milling of the powder, and the milling time was adjusted to $5 \mathrm{~h}$ at high rotation speed of 5,000 rpm as this procedure has previously been proven to result in the smallest particle size with a narrow size distribution as well as a uniform dispersion of the particles [18]. However, agglomeration of the small particles may counter the desired effects achieved by the decreased particle size in the ceramic slurry, and therefore the ability to control the stability of the dispersion is crucial for the effective processing of optimal ceramic slurries. Zeta potential is a very important physical parameter that influences the stability of the aqueous ceramic slurry, and its relationship to slurry rheology is well established [28-31]. Zeta potential may be understood as the electrical potential of the electric double layer of a surface-charged particle and it can be used as the measure of the electrostatic repulsive forces which stabilise the slurry. At low zeta potentials these forces experience a minimum, and thus the maximum in viscosity and shear stress has been found at the vicinity of isoelectric point (iep), the $\mathrm{pH}$ of zero zeta potential $[29,32]$. Since the stability of the dispersion is the highest and the viscosity the lowest at $\mathrm{pH}$ at which the zeta potential deviates the most from the iep, the $\mathrm{pH}$ of the dispersion should be adjusted accordingly.

The cleaning procedure has been found to shift the iep of the Kronos $\mathrm{TiO}_{2}$ powder from 1.7 to more neutral $\mathrm{pH}$, resulting in an iep at 4.8, which is closer to the theoretical values reported for $\mathrm{TiO}_{2}$ [19]. It is well known that many water-soluble impurities, such as phosphates, may cause a substantial shift in the iep, particularly in concentrated suspensions [33, 34]. Therefore, it is likely that the observed shift in the iep of Kronos $\mathrm{TiO}_{2}$ powder was caused by the reduction of adsorbed phosphate ions on the particle surfaces due to the cleaning process. However, sodium was detected in the powder in relatively high quantities after the cleaning. Sodium, at relatively strong ionic strengths, has been found to affect the viscosity, particularly in alkaline $\mathrm{pH}$ range, and shift the iep toward higher $\mathrm{pH}$ values in $\mathrm{TiO}_{2}$ dispersions [35-37]. When dispersing the $\mathrm{TiO}_{2}$ powder at $\mathrm{pH} 9-11$, the behaviour of the slurry changed abruptly after half of the powder was dispersed and the dispersion became coagulated. However, normal viscosity was restored when the $\mathrm{pH}$ was adjusted to 1.7 with additions of acid $(\mathrm{HCl})$. According to Sabetrasekh et al. [19] the zeta potential of the $\mathrm{TiO}_{2}$ raw powder reaches values below $-60 \mathrm{mV}$ at $\mathrm{pH}$ above 8 , while at $\mathrm{pH}$ 1.7 it is only $+30 \mathrm{mV}$. Zeta potential of $\pm 45 \mathrm{mV}$ has been found sufficient to maintain stability in anatase dispersions 
at low ionic strengths, although using lower solid content [36]. It may be that the amount of sodium ions, which remained from the cleaning procedure, increased above the critical concentration in the dispersion as more powder was added, thus reducing the stability and rheological properties of the slurry.

Solid content also influences the stability of the dispersion. At high solid content, the repulsive forces between the surface-charged particles decrease due to overlapping and compression of the electric double layer as the particle separation distance in the slurry approaches the double layer thickness [33, 38]. Since very high solid contents $(\sim 70 \mathrm{wt} \%)$ are used in the preparation of the $\mathrm{TiO}_{2}$ slurry, the relatively poor stability may be further reduced as the particles become smaller and the particle separation distance reduces during milling with the lab dissolver, thus resulting in the flocculation of the finer particles in the slurry. Therefore, despite the long stirring time, the reduction in particle size did not prove as effective as previously reported [18]. Instead, the particle size was found to reach a minimum after only $1 \mathrm{~h}$ of high speed stirring and further stirring only increased the average particle size to a certain level due to the agglomeration of the smallest particles (Fig. 1). After $6.5 \mathrm{~h}$ milling time, the dispersion coagulated and the amount of finer particles in the slurry increased notably. However, these finer particles only became detectable after storing diluted slurry samples for $24 \mathrm{~h}$ prior to particle size measurement, indicating the flocculated state of these particles in undiluted slurry. Thus, the stability of the slurry needs to be improved in order to produce slurries with finer particle sizes. This may be achieved by optimising the cleaning procedure: total removal of sodium from the powder with more vigorous rinsing should lead to better stability at $\mathrm{pH}$ range 7-9, where zeta potentials below $-50 \mathrm{mV}$ may be reached with minimal addition of alkaline solution, such as $\mathrm{NaOH}$. It was also evident that the impeller of the lab dissolver was rather inefficient in milling the powder particles. Replacing the impeller with a better designed rotor blade should, together with improved slurry stability, result in reduced particle size in the $\mathrm{TiO}_{2}$ slurry.

\subsection{Scaffold fabrication}

One of the key steps in the replication process is the preparation of ceramic slurry with suitable properties for coating the polymer sponge as uniformly as possible. The quality of the ceramic coating on the polymer template is strongly dependent on the rheological properties, such as the viscosity, of the ceramic slurry [39]. As was previously mentioned, solid content and stability of the dispersion are the most important parameters that affect the rheological properties. In the present study, it was observed that even a small change in the solid content resulted in altered sponge loading. As the $\mathrm{TiO}_{2}$-to- $\mathrm{H}_{2} \mathrm{O}$ ratio was increased from 2.4 to 2.6, the viscosity of the slurry increased notably. From the SEM and micro-CT analyses, it was observed that the slurry with increased solid content resulted in a thicker and more uniform coating on the polymer sponge. The improved compressive strength values of the scaffolds fabricated from the denser slurry seem to verify the notion of the more favourable sponge loading achieved using the slurry with increased $\mathrm{TiO}_{2} / \mathrm{H}_{2} \mathrm{O}$ ratio. With better control of the dispersion stability, slurries with higher solid content may possibly be prepared while maintaining the optimal rheological properties. This may lead to further enhancement in the sponge loading.

Mechanical pressing was used instead of centrifuging to remove the excess $\mathrm{TiO}_{2}$ slurry from the polymer templates. This method was found more suitable due to the relatively high viscosity of the slurry and also resulted in a thicker coating on the foam strut. This explains the notable increase in the strut thickness of the fabricated $\mathrm{TiO}_{2}$ scaffolds in comparison to the average strut thickness reported in an earlier study [18], which contributed to the improved mechanical strength observed in the present study. Also, since the 60 ppi PU foam was used as the scaffold template instead of 45 ppi PU foam, the resulting scaffolds had a smaller pore size and a higher number of struts per crosssectional area than those produced by Fostad et al. [18], which partly explains the considerably higher compressive strength of the fabricated $\mathrm{TiO}_{2}$ scaffolds.

As expected, multiple replications resulted in further increase in the compressive strength. For recoating, thinner slurry was prepared in order to ensure uniform coating on the scaffold struts, and since the mechanical pressing was not applicable in the case of recoating, the excess slurry was centrifuged out of the ceramic preform. The compressive strength of the scaffolds was notably increased due to the second replication process reaching to the values of 1.63-2.67 MPa at $82-90 \%$ porosities. In comparison, the compressive strength of trabecular bone is typically 2-12 MPa [13]. Nevertheless, the strut thickness and porosity of the scaffolds remained virtually unchanged in spite of the recoating process. One possible explanation for the observed increase in the compressive strength with no apparent change in the strut thickness may be linked to the folded nature of the scaffold struts. During the recoating process, the thinner slurry may be deposited in the folds of the struts, thus strengthening the strut structure without causing an apparent change in the strut diameter. Wherefore, subsequent recoating processes are anticipated to cause a detectable increase in the strut thickness. The observed decrease in the fractal dimension of the scaffolds struts seems to verify this since the added coating layer in the folds reduces the complexity of the strut structure. The 
strong correlation between strength and fractal dimension remains positive as a more noticeable increase in fractal dimension was observed due to the increase in the solid content. In addition, the recoating process eliminates large flaws, such as cracks and voids, remaining in the ceramic foam structure after the first replication. As the cracks and voids in the ceramic body have a debilitating effect on the mechanical properties, the removal of these flaws, or even the reduction in the flaw size, is expected to contribute to significantly improved strength values [40]. The recoating was found to have only a negligible effect on the interconnectivity of the scaffold. Nonetheless, repeated recoating processes are expected to cause further reduction in the interconnectivity of the $\mathrm{TiO}_{2}$ scaffolds, particularly at larger minimum connection sizes [18]. This is due to decreased porosity and blocking of pore openings as a result of the increasing strut thickness [41].

\subsection{Pore architecture}

In bone tissue engineering, the scaffold must provide an optimal microenvironment for osteogenesis. Therefore, a non-degradable scaffold intended for this purpose should exhibit a highly interconnected pore structure with porosity higher than $70 \%$ and an average pore size exceeding $300 \mu \mathrm{m}$ to ensure viable vascularisation and bone formation through the entire scaffold [42, 43]. The fabricated $\mathrm{TiO}_{2}$ scaffolds had average pore sizes close to $400 \mu \mathrm{m}$ and porosities between 76 and $94 \%$. Therefore, these scaffolds are expected to allow sufficient tissue ingrowth and vascularisation for bone regeneration. Moreover, the remarkably high interconnectivity ( $>92 \%$ ) through connections as large as $200 \mu \mathrm{m}$ is more than likely to allow for excellent permeability, and therefore, to guarantee sufficient transport of nutrients and metabolism products for viable osteogenesis within the scaffold interior. Interconnectivity values above $95 \%$ have previously been reported for various bone scaffolds at similar porosities with the fabricated $\mathrm{TiO}_{2}$ scaffolds [20, 44, 45]. However, as the minimum connection size was increased to $200 \mu \mathrm{m}$, the accessible pore volume generally reduced more drastically than was seen in the case of the $\mathrm{TiO}_{2}$ scaffolds. Shi et al. [44] reported interconnectivity of less than $80 \%$ through openings larger than $200 \mu \mathrm{m}$, while the accessible pore volume was found to be less than $60 \%$ at the same minimum connection size in a study conducted by Hacker et al. [45].

\section{Conclusions}

Highly porous and well interconnected $\mathrm{TiO}_{2}$ scaffolds were fabricated using polymer sponge method. The fabricated scaffolds displayed compressive strength values above
2.5 $\mathrm{MPa}$ at $80-90 \%$ porosities. Considerable improvement was therefore observed in the compressive strength of the fabricated scaffolds in comparison to the strength values previously reported for $\mathrm{TiO}_{2}$ bone scaffolds. The improved strength was achieved by the optimisation of the processing parameters and without compromising the high porosity or the desired pore architectural features. Properties of the ceramic slurry, such as solid content, viscosity, and particle size distribution, are some of the key processing parameters that govern the strength of the ceramic foams. Recoating of the ceramic foams is another important processing step in producing foams with improved mechanical properties. Due to the high porosity and extremely high interconnectivity of the fabricated $\mathrm{TiO}_{2}$ scaffolds, the compressive strength of the $\mathrm{TiO}_{2}$ scaffolds may be improved even further with multiple recoating processes. However, subsequent recoating processes are anticipated to cause a detectable increase in the strut thickness, wherefore the desired pore architectural features, such as pore size, porosity, and interconnectivity, may eventually be compromised. Improvement in the stability of the ceramic slurry may also allow further enhancement in mechanical strength due to improved microstructure of the ceramic. Combined with the excellent biocompatibility and bioactive properties of $\mathrm{TiO}_{2}$, the highly interconnected pore structure of the scaffolds is expected to provide an excellent microenvironment for bone regeneration. Therefore, the fabricated $\mathrm{TiO}_{2}$ foams show great promise as loadbearing scaffolds for bone tissue engineering applications where moderate mechanical support is required.

Acknowledgments This study was supported by Eureka-Eurostars Project Application E!5069 NewBone. The authors acknowledge Mr. Martin F. Sunding (Department of Physics, University of Oslo) and Dr. Ola Nilsen (Department of Chemistry, University of Oslo) for their assistance with the XPS and XRD analysis, respectively. Also many thanks to Mr. Geir Hansen (Malvern Instruments Nordic AB) for borrowing his Mastersizer 2000 at no charge.

Open Access This article is distributed under the terms of the Creative Commons Attribution Noncommercial License which permits any noncommercial use, distribution, and reproduction in any medium, provided the original author(s) and source are credited.

\section{References}

1. Hutmacher DW, Schantz JT, Lam CXF, Tan KC, Lim TC. State of the art and future directions of scaffold-based bone engineering from a biomaterials perspective. J Tissue Eng Regen M. 2007;1(4):245-60.

2. Jones JR, Hench LL. Regeneration of trabecular bone using porous ceramics. Curr Opin Solid State Mater Sci. 2003;7(4-5): 301-7.

3. Hutmacher DW. Scaffolds in tissue engineering bone and cartilage. Biomaterials. 2000;21(24):2529-43. 
4. Kim B-S, Mooney DJ. Development of biocompatible synthetic extracellular matrices for tissue engineering. Trends Biotechnol. 1998;16(5):224-30.

5. Kuboki Y, Takita H, Kobayashi D, Tsuruga E, Inoue M, Murata M, et al. BMP-induced osteogenesis on the surface of hydroxyapatite with geometrically feasible and nonfeasible structures: topology of osteogenesis. J Biomed Mater Res. 1998;39(2): 190-9.

6. Hollister SJ, Maddox RD, Taboas JM. Optimal design and fabrication of scaffolds to mimic tissue properties and satisfy biological constraints. Biomaterials. 2002;23(20):4095-103.

7. Hing KA, Annaz B, Saeed S, Revell PA, Buckland T. Microporosity enhances bioactivity of synthetic bone graft substitutes. J Mater Sci Mater Med. 2005;16(5):467-75.

8. Jerome R, Maquet V. Design of macroporous scaffolds for cell transplantation. Mater Sci Forum. 1997;250:15-42.

9. Lu JX, Flautre B, Anselme K, Hardouin P, Gallur A, Descamps $\mathrm{M}$, et al. Role of interconnections in porous bioceramics on bone recolonization in vitro and in vivo. $\mathrm{J}$ Mater Sci Mater Med. 1999;10(2):111-20.

10. Yang S, Leong K-F, Du Z, Chua C-K. The design of scaffolds for use in tissue engineering. Part 1. Traditional factors. Tissue Eng. 2001;7(6):679-89.

11. Torres FG, Nazhat SN, Sheikh Md Fadzullah SH, Maquet V, Boccaccini AR. Mechanical properties and bioactivity of porous $\mathrm{PLGA}_{\mathrm{TiO}}$ nanoparticle-filled composites for tissue engineering scaffolds. Compos Sci Technol. 2007;67(6):1139-47.

12. Cowan CM, Soo C, Ting K, Wu B, Gerald PS. Evolving concepts in bone tissue engineering. Current topics in developmental biology. San Diego: Academic Press; 2005. p. 239-85.

13. Jones JR, Ehrenfried LM, Hench LL. Optimising bioactive glass scaffolds for bone tissue engineering. Biomaterials. 2006;27(7): 964-73.

14. Barrère F, Mahmood TA, de Groot K, van Blitterswijk CA. Advanced biomaterials for skeletal tissue regeneration: instructive and smart functions. Mater Sci Eng, R. 2008;59(1-6): 38-71.

15. Nygren $\mathrm{H}$, Tengvall $\mathrm{P}$, Lundstrom $\mathrm{I}$. The initial reactions of $\mathrm{TiO}_{2}$ with blood. J Biomed Mater Res. 1997;34(4):487-92.

16. Jokinen M, Pätsi M, Rahiala H, Peltola T, Ritala M. Influence of sol and surface properties on in vitro bioactivity of sol-gelderived $\mathrm{TiO}_{2}$ and $\mathrm{TiO}_{2}-\mathrm{SiO}_{2}$ films deposited by dip-coating method. J Biomed Mater Res. 1998;42(2):295-302.

17. Haugen H, Will J, Kohler A, Hopfner U, Aigner J, Wintermantel E. Ceramic $\mathrm{TiO}_{2}$-foams: characterisation of a potential scaffold. J Eur Ceram Soc. 2004;24(4):661-8.

18. Fostad G, Hafell B, Førde A, Dittmann R, Sabetrasekh R, Will J, et al. Loadable $\mathrm{TiO}_{2}$ scaffolds-a correlation study between processing parameters, micro $\mathrm{CT}$ analysis and mechanical strength. J Eur Ceram Soc. 2009;29(13):2773-81.

19. Sabetrasekh R, Tiainen H, Reseland JE, Will J, Ellingsen JE, Lyngstadaas SP, et al. Impact of trace elements on biocompatibility of titanium scaffolds. Biomed Mater. 2010. doi:10.1088/ 1748-6041/5/1/015003.

20. Moore MJ, Jabbari E, Ritman EL, Lu L, Currier BL, Windebank $\mathrm{AJ}$, et al. Quantitative analysis of interconnectivity of porous biodegradable scaffolds with micro-computed tomography. J Biomed Mater Res A. 2004;71A(2):258-67.

21. Cohen J. Statistical power analysis for the behavioral sciences. 2nd ed. Hillsdale, NJ: Lawrence Erlbaum Associates; 1988.

22. Mikkola P, Ylha P, Levanen E, Rosenholm JB. Effect of impurities on dispersion properties of alpha-alumina powder. Ceram Int. 2004;30(2):291-9.

23. Bae SI, Baik S. Critical concentration of $\mathrm{MgO}$ for the prevention of abnormal grain-growth in alumina. J Am Ceram Soc. 1994; 77(10):2499-504.
24. Chi MF, Gu H, Qian PX, Wang X, Wang PL. Effect of $\mathrm{TiO}_{2}-$ $\mathrm{SiO}_{2}$ distribution on bimodal microstructure of $\mathrm{TiO}_{2}$-doped alpha- $\mathrm{Al}_{2} \mathrm{O}_{3}$ ceramics. Z Metallk. 2005;96(5):486-92.

25. Horn RG. Surface forces and their action in ceramic materials. J Am Ceram Soc. 1990;73(5):1117-35.

26. Montanaro L, Jorand Y, Fantozzi G, Negro A. Ceramic foams by powder processing. J Eur Ceram Soc. 1998;18(9):1339-50.

27. Sergent JE. Ceramic materials. Ceramic interconnect technology handbook. Boca Raton: Taylor and Francis Group; 2007. p. 163-98.

28. Yuping $\mathrm{Z}$, Dongliang J, Greil $\mathrm{P}$. Tape casting of aqueous $\mathrm{Al}_{2} \mathrm{O}_{3}$ slurries. J Eur Ceram Soc. 2000;20(11):1691-7.

29. Hunter RJ, Nicol SK. Dependence of plastic flow behavior of clay suspensions on surface properties. J Colloid Interface Sci. 1968;28(2):250-9.

30. Firth BA. Flow properties of coagulated colloidal suspensions. 2. Experimental properties of flow curve parameters. J Colloid Interface Sci. 1976;57(2):257-65.

31. Morris GE, Skinner WA, Self PG, Smart RS. Surface chemistry and rheological behaviour of titania pigment suspensions. Colloid Surf A Physicochem Eng Asp. 1999;155(1):27-41.

32. Leong YK, Boger DV, Parris D. Surface-chemistry and rheological properties of zirconia suspensions. J Rheol. 1991;35(1):149-65.

33. Kosmulski M, Rosenholm JB. Electroacoustic study of adsorption of ions on anatase and zirconia from very concentrated electrolytes. J Phys Chem. 1996;100(28):11681-7.

34. Gustafsson J, Nordenswan E, Rosenholm JB. Shear-induced aggregation of anatase dispersions investigated by oscillation and low shear rate viscometry. J Colloid Interface Sci. 2001;242(1):82-9.

35. Gustafsson J, Mikkola P, Jokinen M, Rosenholm JB. The influence of $\mathrm{pH}$ and $\mathrm{NaCl}$ on the zeta potential and rheology of anatase dispersions. Colloid Surf A Physicochem Eng Asp. 2000;175(3):349-59.

36. Gustafsson J, Nordenswan E, Rosenholm JB. Consolidation behavior in sedimentation of $\mathrm{TiO}_{2}$ suspensions in the presence of electrolytes. J Colloid Interface Sci. 2003;258(2):235-43.

37. Kosmulski M, Gustafsson J, Rosenholm JB. Correlation between the zeta potential and rheological properties of anatase dispersions. J Colloid Interface Sci. 2001;233(2):367-8.

38. Pollinger JP. Oxide and non-oxide processing applications using electroacoustic characterization. In: Malghan SG, editor. NIST Special Publications No. 856, electroacoustics for characterization of particulates and suspensions. Washington, DC: US Government Printing Office; 1993.

39. Zhu X, Jiang D, Tan S. The control of slurry rheology in the processing of reticulated porous ceramics. Mater Res Bull. 2002;37(3):541-53.

40. Zhu XW, Jiang DL, Tan SH, Zhang ZQ. Improvement in the strut thickness of reticulated porous ceramics. J Am Ceram Soc. 2001;84(7):1654-6.

41. Kim H-W, Lee S-Y, Bae C-J, Noh Y-J, Kim H-E, Kim H-M, et al. Porous $\mathrm{ZrO}_{2}$ bone scaffold coated with hydroxyapatite with fluorapatite intermediate layer. Biomaterials. 2003;24(19):3277-84.

42. Karageorgiou V, Kaplan D. Porosity of 3D biomaterial scaffolds and osteogenesis. Biomaterials. 2005;26(27):5474-91.

43. Byrne DP, Lacroix D, Planell JA, Kelly DJ, Prendergast PJ. Simulation of tissue differentiation in a scaffold as a function of porosity, Young's modulus and dissolution rate: application of mechanobiological models in tissue engineering. Biomaterials. 2007;28(36):5544-54.

44. Shi X, Sitharaman B, Pham QP, Liang F, Wu K, Edward Billups $\mathrm{W}$, et al. Fabrication of porous ultra-short single-walled carbon nanotube nanocomposite scaffolds for bone tissue engineering. Biomaterials. 2007;28(28):4078-90.

45. Hacker M, Ringhofer M, Appel B, Neubauer M, Vogel T, Young $\mathrm{S}$, et al. Solid lipid templating of macroporous tissue engineering scaffolds. Biomaterials. 2007;28(24):3497-507. 